
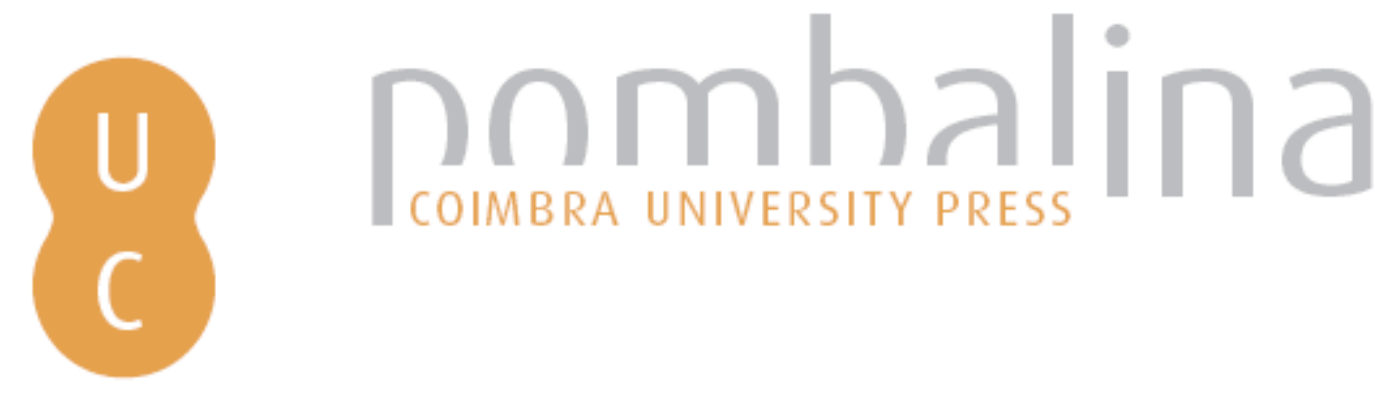

\title{
A perspetiva forense da autópsia bucal
}

Autor(es): $\quad$ Oliveira, Carina; Santos, César; Vieira, Duarte Nuno

Publicado por: Imprensa da Universidade de Coimbra

URL

persistente:

URI:http://hdl.handle.net/10316.2/38478

DOI:

DOI:http://dx.doi.org/10.14195/978-989-26-0963-8_7

Accessed : $\quad$ 26-Apr-2023 12:13:59

A navegação consulta e descarregamento dos títulos inseridos nas Bibliotecas Digitais UC Digitalis, UC Pombalina e UC Impactum, pressupõem a aceitação plena e sem reservas dos Termos e Condições de Uso destas Bibliotecas Digitais, disponíveis em https://digitalis.uc.pt/pt-pt/termos.

Conforme exposto nos referidos Termos e Condições de Uso, o descarregamento de títulos de acesso restrito requer uma licença válida de autorização devendo o utilizador aceder ao(s) documento(s) a partir de um endereço de IP da instituição detentora da supramencionada licença.

Ao utilizador é apenas permitido o descarregamento para uso pessoal, pelo que o emprego do(s) título(s) descarregado(s) para outro fim, designadamente comercial, carece de autorização do respetivo autor ou editor da obra.

Na medida em que todas as obras da UC Digitalis se encontram protegidas pelo Código do Direito de Autor e Direitos Conexos e demais legislação aplicável, toda a cópia, parcial ou total, deste documento, nos casos em que é legalmente admitida, deverá conter ou fazer-se acompanhar por este aviso.

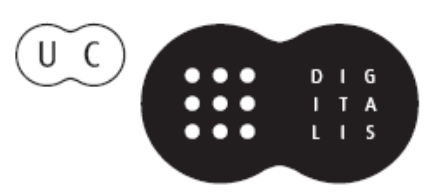




\section{IDENTIFICAÇÃO EM MEDICINA DENTÁRIA FORENSE}

ANA CORTE-REAL DUARTE NUNO VIEIRA COORDENAÇÃO 
Capítulo VII

A perspetiva forense da autópsia bucal

Aspetos gerais de autópsia

Técnicas de autópsia bucal

Processo de identificação humana

Limitações

Perspetivas futuras

Carina Oliveira

César Santos

Duarte Nuno Vieira 


\section{RESUMO:}

A individualidade da dentição humana e a sua elevada resistência permitem que esta seja considerada relevante na identificação de cadáveres, nomeadamente em situações de acentuado estado de degradação. Porém, as dificuldades de acesso aos registos dentários ante mortem adequadamente preenchidos, caso existam, constituem a principal limitação técnica no processo de identificação. Para obtenção dos elementos necessários procede-se à autópsia bucal, tendo sido descritas várias técnicas possíveis de abordagem, que proporcionam maior ou menor preservação da fisionomia facial, aspeto que poderá ser importante. A aplicação de técnicas de virtópsia poderá constituir um complemento ao estudo autóptico convencional, quer para efeitos de identificação quer para esclarecimento da causa de morte. Em suma, a Medicina Dentária Forense constitui uma área particularmente relevante das Ciências Forenses, permitindo analisar diversas questões de interesse criminal e social, nomeadamente no que se refere à identificação humana em contextos de elevada degradação cadavérica.

\section{PALAVRAS-CHAVE:}

técnicas autópticas, identificação humana, abuso físico, causa de morte, virtópsia.

\section{ABSTRACT:}

The high resistance and uniqueness of the human dentition allows it to be considered relevant in identifying corpses with an advanced state of decomposition. However, the difficulties of access to properly filled ante mortem dental records (if existent), are the main technical limitation in the identification process. To obtain the necessary elements oral autopsy is proceeded, approaching several possible techniques that provide greater or lesser preservation of the facial features. This aspect may be especially relevant in cases where is necessary a subsequent visual recognition. The application of virtopsy techniques could provide a complement to the conventional autopsy either for identification or to clarify the cause of death. In summary, Forensic Dentistry is a particularly relevant area of Forensic Sciences, allowing the analysis of several criminal and social issues, particularly with regard to human identification in contexts of advanced cadaverous breakdown.

\section{KEYWORDS:}

autopsy techniques, human identification, physical abuse, cause of death, virtual autopsy. 


\section{VII.1. INTRODUÇÃO}

A Medicina Dentária Forense e, por inerência, o médico dentista forense, desempenham um papel relevante na investigação médico-legal, em particular nos processos de identificação humana [1].

O reconhecimento visual do cadáver, frequentemente usado para fins de identificação, deve suscitar assinaláveis reservas, e tem estado na origem de perturbantes equívocos, sobretudo em situações relativas a desastres de massa. Atualmente são já poucos os países onde o reconhecimento visual continua a ser utilizado neste domínio como elemento único de identificação [2].

Os países com uma medicina legal desenvolvida dispõem hoje de métodos sofisticados de análise forense, culminando na determinação do perfil genético a partir de amostras obtidas da dentina, cemento e polpa dentária [3-6]. Porém, face às limitações económicas de alguns deles, que não dispõem de recursos suficientes para a aquisição e instalação dos equipamentos necessários, as equipas de investigação tendem a dirigir os seus esforços no sentido de utilizar métodos mais económicos, mas passíveis de proporcionarem dados que permitem uma identificação positiva.

Nas últimas décadas, a identificação das vítimas a partir da análise da morfologia dentária tem sido reconhecida como um dos métodos mais fiáveis $[7,8]$ e menos dispendiosos, com resultados tão exatos quanto os obtidos, por exemplo, com o recurso à dactiloscopia [9].

Em virtude da multiplicidade de características individualizantes dos dentes poder-se-á considerar num determinado universo de sujeitos que não existem dois indivíduos com idêntica dentadura e que, para além disso, existem diversos elementos, tais como, ausência de dentes, agenesia, anomalias da sua forma ou posição, presença de cáries, fraturas, desgastes e depressões, que contribuem para a sua singularidade $[8,10]$. Acresce que em determinadas situações, os dentes são os únicos elementos passíveis de serem utilizados para identificação, uma vez que se encontram anatomicamente protegidos por tecidos orais, bem como por serem estruturalmente resistentes à putrefação, degradação e a agentes físicos e químicos lesivos (chama, ácidos e bases fortes, entre outros). Por outro lado, os materiais dentários são, também eles, muito resistentes às condições adversas, tal como assinalado nas indicações da Federação Dentária Internacional $[9,11]$.

Em termos genéricos, o processo de identificação humana neste âmbito engloba o estudo comparativo dos elementos obtidos no período post mortem com os registos médicos e dentários ante mortem, eventualmente complementado com a recolha de amostras biológicas para determinação do perfil genético $[8,12,13]$. Quando os registos dentários ante mortem estão indisponíveis ou incompletos, é fundamental que as técnicas autópticas procurem preservar a fisionomia facial do cadáver, atenuando na medida do possível uma eventual desfiguração e facilitando, desse modo, o posterior reconhecimento visual por familiares ou conhecidos [13].

No presente capítulo serão abordados os aspetos gerais do exame necrópsico forense, com particular ênfase na autópsia bucal, sendo tecidas ainda algumas reflexões sobre as principais dificuldades inerentes à realização do exame intraoral, nomeadamente em situações de cadáveres carbonizados ou em avançado estado 
A

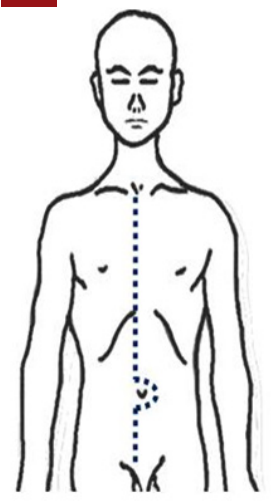

B

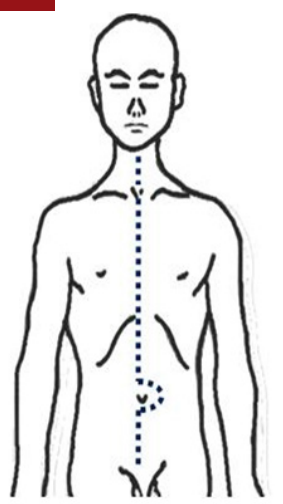

C

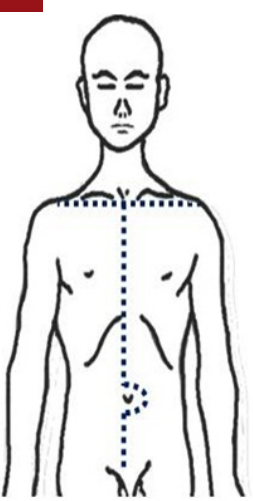

D

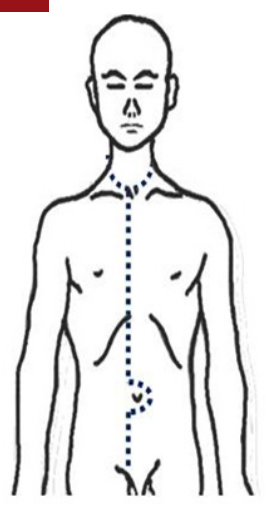

E

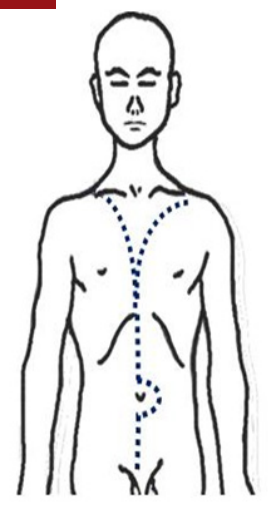

Figura VII.1 - Principais modalidades de abertura do cadáver. Da esquerda para a direita: (A) incisão esterno-púbica; (B) incisão mento-púbica; (C) incisão em T (biacromial); (D) incisão inframandibular (bimastoideia); (E) incisão em Y.

de putrefação. Por último, efetuar-se-á uma referência às limitações do método e ao papel que as novas tecnologias poderão assumir no processo de identificação humana.

\section{VII.2. ASPETOS GERAIS DE AUTÓPSIA}

O exame necrópsico forense pressupõe a realização de um exame completo, sistematizado e minucioso do cadáver, que se inicia pelo exame do vestuário, do hábito externo, prosseguindo com a abertura e exame das cavidades craniana, torácica, abdominal (acrescida da abertura dos membros e da coluna caso existam lesões a estes níveis), evisceração dos respetivos órgãos [14] e estudo individualizado de cada um destes.
Para a abertura do cadáver, começa-se por efetuar uma incisão cutânea, usando um bisturi, desde a fúrcula esternal à sinfíse púbica contornando a cicatriz umbilical. Este corte poderá ser completado de três modos: (i) por prolongamento superior da incisão inicial até à sínfise mentoniana; (ii) efetuando uma incisão biacromial unida ao corte inicial ao nível da fúrcula, formando um padrão em T; (iii) realizando uma incisão bimastoideia, na qual se descreve um semicírculo de concavidade superior unido na porção mais inferior à incisão inicial. Alternativamente, poderá ser efetuada uma incisão em $Y$, a partir do apêndice xifóideu, prolongando-se os dois ramos superiores em direção aos processos acromiais [15] (fig. VII.1).

O tipo de incisão a aplicar depende das práticas adotadas no local de trabalho pelo 

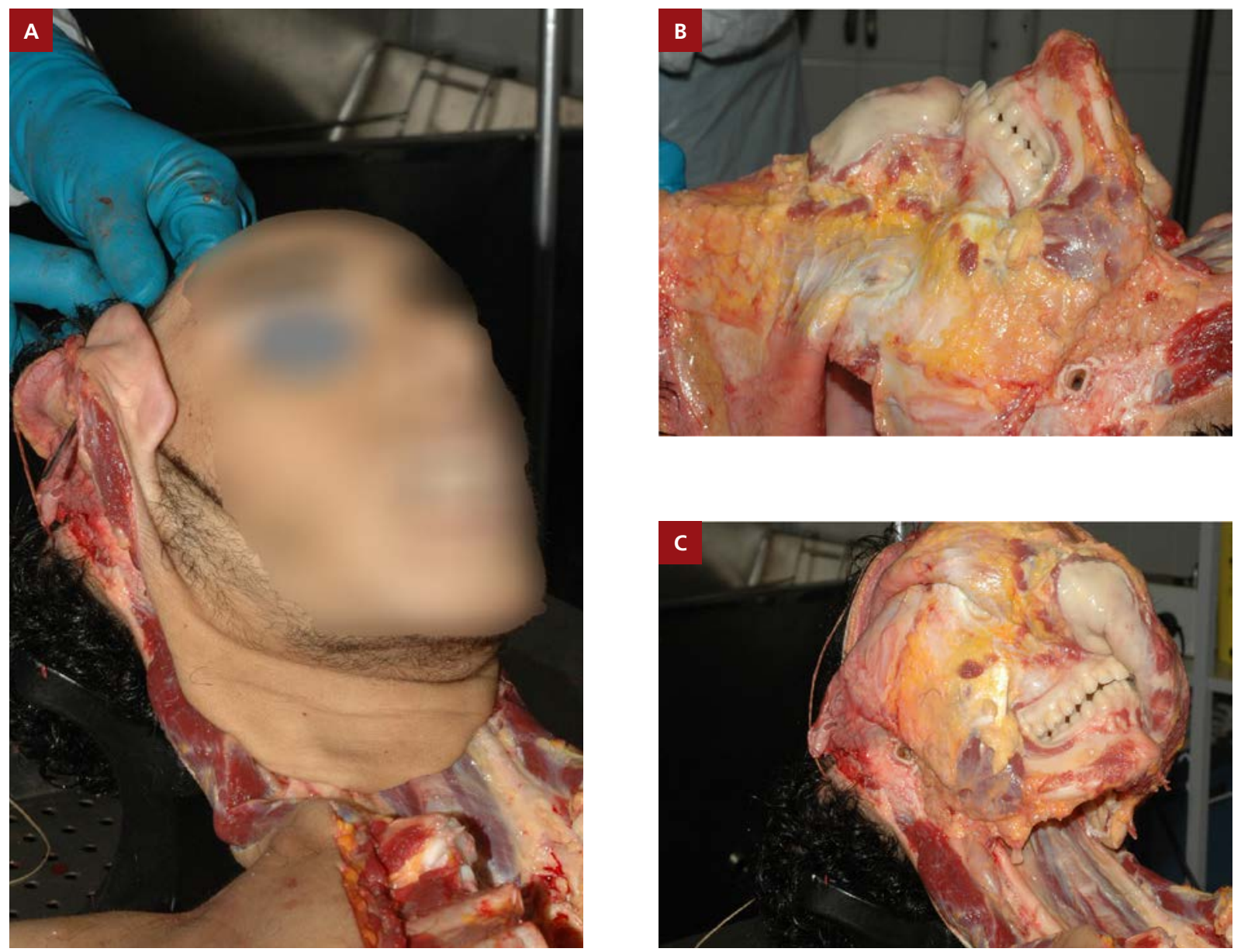

Figura VII. 2 - Técnica de incisão bimastoideia para a exposição das estruturas cervicais, com consequente ampliação da disseção para os tecidos faciais. (A) Fotografia na fase inicial da técnica. (B) Fotografia na fase final da técnica, em perfil antero-lateral direito. (C) Fotografia em perfil lateral direito. Cortesia do INMLCF, I.P. 2013.

patologista forense, da sua preferência pessoal ou da necessidade de preservar e explorar determinados detalhes anatomopatológicos. Os autores, por exemplo, recorrem à técnica da incisão bimastóideia para exposição das estruturas cervicais, nos casos de suspeita de compressão extrínseca do pescoço. Esta técnica tem ainda a virtualidade de permitir ampliar a disseção cervical para os tecidos faciais (fig. VII.2).

No sentido de completar a exposição sobre a técnica geral de autópsia, é de referir que na literatura se mencionam quatro técnicas principais de remoção de orgãos: (i) Técnica de Letulle disseção em bloco, com separação e posterior 
disseção dos órgãos; (ii) Técnica de Ghon - disseção em blocos separados (cardiopulmonar, abdominal, genito-urinário) e disseção posterior dos órgãos; (iii) Técnica Virchow - remoção individual dos órgãos; (iv) Técnica de Rokitansky - disseção in situ dos orgãos [15]. Em Portugal, a técnica de Virchow é a mais usual, aplicando-se formas modificadas da técnica de Ghon conforme os casos. Relativamente à técnica de Rokitanksy, de escasso relevo em termos da literatura [15], vislumbra-se que possa ter utilidade em situações em que se recomende uma manipulação mínima do cadáver, como por exemplo, na suspeita de doenças infetocontagiosas de fácil disseminação [16].

No decurso da autópsia, é fundamental a realização de um registo fotográfico, devendo o mesmo preceder qualquer técnica invasiva que possa alterar ou destruir de forma irrecuperável qualquer informação relevante $[8,13]$. Por outro lado, as fotografias permitem recolher elementos identificativos úteis para o método visual, obviando a necessidade de um contato direto entre os familiares ou conhecidos e os restos cadavéricos [13]. Associado à autópsia bucal, preconiza-se a concretização, no mínimo, de fotografias da face extraorais (frontal, perfil $45^{\circ}$ e perfil $90^{\circ}$ ) e intraorais [17].

O exame imagiológico é, igualmente, pertinente, sugerindo-se que sejam incluídas radiografias simples do crânio na norma fronto-lateral, panorâmica e radiografias apicais [18]. No que se refere às radiografias intraorais, estas permitem avaliar com maior detalhe características individualizantes dos dentes, designadamente a morfologia das restaurações, a anatomia dentária, coronária e radicular, tratamentos endodônticos e formato dos seios maxilares [8, 19, 20].
Por outro lado, as peças dentárias expostas a ação de agentes térmicos, em particular se intensa ou durante um longo período de tempo, ficam estruturalmente mais frágeis [21]. Pelo menos nestes casos, é recomendável a reprodução das arcadas dentárias por modelos em gesso antes de qualquer manipulação que possa ocasionar perdas irreversíveis, os quais servirão como meios de comparação com modelos ante mortem.

De referir, ainda, que todo o material protético ou ortodôntico deverá ser removido do cadáver, procedendo-se à análise das suas características, nomeadamente, o desenho, o número de elementos protéticos e relações interdentárias, localização anatómica, se fixo ou removível e nível de desgaste do material [13].

\section{VII.3. TÉCNICAS DE AUTÓPSIA BUCAL}

Centremo-nos agora, concretamente, na autópsia bucal, que não constituindo uma prática frequente da autópsia médico-legal, adquire particular importância nas situações anteriormente referidas. É neste contexto que se afigura relevante a integração de um médico dentista na equipa de investigação forense.

Na literatura encontram-se descritas algumas técnicas de autópsia bucal, dependendo a escolha do estado de preservação da cabeça do cadáver [22], nomeadamente, nos casos de traumatismo orofacial ou carbonizados. Neste contexto, refira-se que Silver-Souviron [15] desenvolveu uma classificação da condição do corpo no momento do exame (tab. VII.1). 
Tabela VII.1 - Estado cadavérico de acordo com a classificação de Silver-Souviron [15].

\section{CLASSE I (Cadáver fresco)}

\begin{tabular}{|l|l|}
\hline Subclasse $A^{*}$ & $\begin{array}{l}\text { Boa preservação da face e estruturas dentárias, sendo passível de } \\
\text { reconhecimento visual pelos familiares. }\end{array}$ \\
\hline Subclasse B* & $\begin{array}{l}\text { Exposto a elevada energia cinética (acidentes aéreos, de viação, } \\
\text { ferroviários ou agentes explosivos), sem exposição prolongada à } \\
\text { água ou ao fogo. As arcadas dentárias podem estar fragmentadas } \\
\text { e dispersas por uma extensa área. }\end{array}$ \\
\hline CLASSE II (Cadáver decomposto ou carbonizado) & $\begin{array}{l}\text { Exposto a diversos elementos, designadamente fogo, água, clima, } \\
\text { ação de insetos ou outros animais. Degradação mais ou menos extensa } \\
\text { dos tecidos moles. Inviabiliza, de um modo geral, o reconhecimento } \\
\text { visual pelos familiares. }\end{array}$ \\
\hline Subclasse A* & $\begin{array}{l}\text { Exposto à ação de agentes traumáticos ante ou post mortem, com } \\
\text { fragmentação dos tecidos. }\end{array}$ \\
\hline CLASSE III (Cadáver esqueletizado) & $\begin{array}{l}\text { Podem não se encontrar preservados todos os elementos ósseos, } \\
\text { em particular se o cadáver esteve exposto ao meio ambiente. } \\
\text { As arcadas dentárias podem permanecer preservadas durante longos } \\
\text { períodos de tempo. }\end{array}$ \\
\hline Subclasse A* & $\begin{array}{l}\text { Restos esqueletizados fragmentados, podendo esta condição advir } \\
\text { da própria ação predatória animal. }\end{array}$ \\
\hline Subclasse B*
\end{tabular}

* Subclasse A: Cádaver íntegro

* Subclasse B: Cádaver fragmentado

A autópsia bucal inicia-se com o exame do hábito externo da face, durante o qual se devem pesquisar possíveis assimetrias, mobilidades ósseas anormais, lacerações ou elementos que possam, inclusivamente, sugerir a causa de morte [23]. A presença de edema ou equimoses a nível do andar inferior da face são elementos sugestivos de fratura mandibular, principalmente se associados a mobilidade anormal da mandíbula, crepitação e assimetria facial [24].

Deve ser dada particular atenção à inspeção da face, uma vez que é uma área frequentemente atingida em casos de abuso físico [25]. Neste contexto, a cavidade oral é geralmente sede de múltiplas lesões, designadamente na tentativa de silenciar uma criança [26], no decurso de uma alimentação forçada [27] ou no ato de apertar ou esfregar violentamente o rosto [28]. As lesões orofaciais, em caso de abuso, podem traduzir-se por equimoses, lacerações, abrasões ou fraturas, por vezes, em diferentes estadios de cicatrização [29]. A utilização de instrumentos contundentes pode provocar um descolamento gengival vestibular [30] e, no contexto de alimentação forçada, podem surgir lesões na mucosa jugal, no pavimento bucal ou no palato [29]. As petéquias 

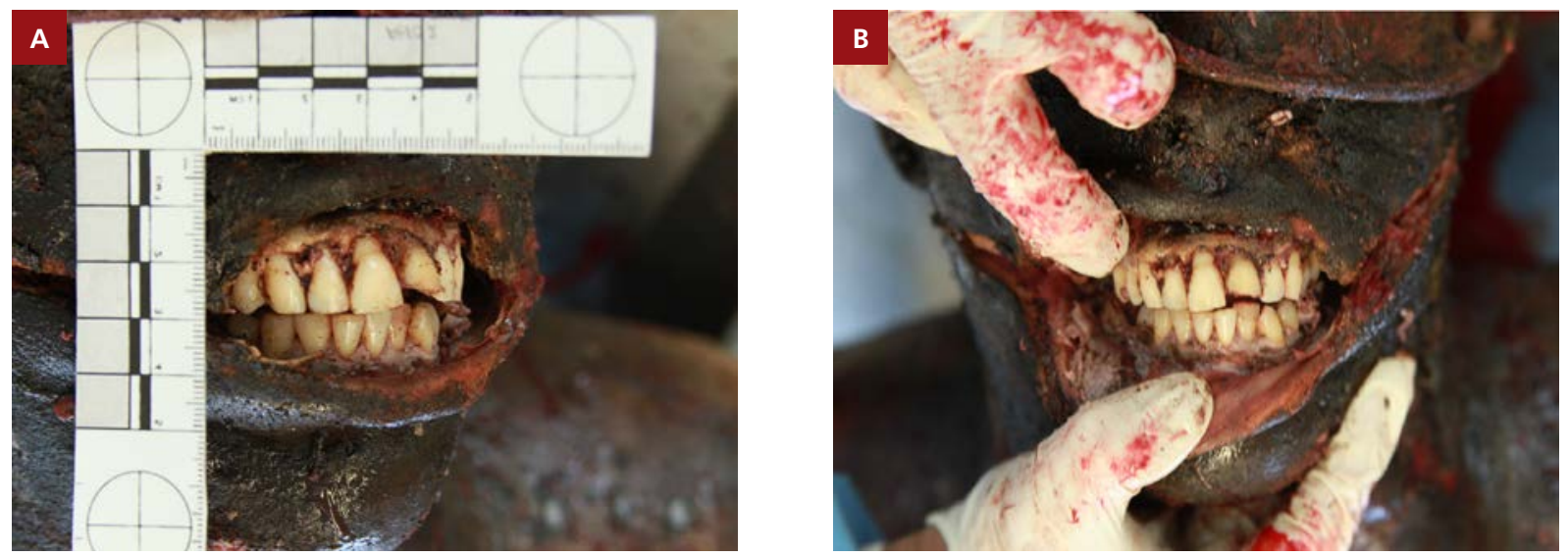

Figuras VII.3 (A e B) - Vista do andar inferior da face em cadáver carbonizado após incisão bilateral única - técnica comissura-tragus. (A) Medição com régua ABFO n². (B) Exposição do vestíbulo. Cortesia do INMLCF, I.P. 2013.

palatinas não são patognomónicas de abuso sexual, devendo ter-se a precaução de excluir essa possibilidade, principalmente se associadas a laceração dos freios [27]. É de realçar que as lacerações dos freios, especialmente dos lábios, podem facilmente passar despercebidas, caso não se proceda à eversão destes [31].

No que se refere às lesões dentárias, estas ocorrem maioritariamente nos dentes anteriores, por ação de um traumatismo direto da mão/punho ou de instrumento introduzido à força na cavidade oral [32]. Contudo, deve ser excluída a etiologia acidental, por confronto com os elementos circunstanciais apurados.

Deve, todavia, ser realçada a dificuldade de acesso à cavidade oral em cadáveres com acentuada rigidez cadavérica, na fase enfisematosa da putrefação ou em cadáveres carbonizados, por retração tecidular [33,34]. Nestes casos, poderá ser realizada uma incisão bilateral única, desde a comissura labial ao pavilhão auricular, de modo a permitir a visualização, in situ, das arcadas dentárias (figs. VII.3).

Em termos genéricos, devem evitar-se técnicas de autópsia passíveis de desfigurar o cadáver, atendendo à eventual necessidade de reconhecimento visual ou à tradicional exposição aos famíliares no decurso das cerimónias fúnebres.

Neste sentido, considera-se aconselhável a realização da técnica inframandibular (incisão bimastóideia), anteriormente descrita, prolongando-se superiormente a disseção até ao nível pretendido (fig. VII.4). Para preservação da fisionomia facial é importante manter pontos de ancoragem ósseos, preferencialmente a 


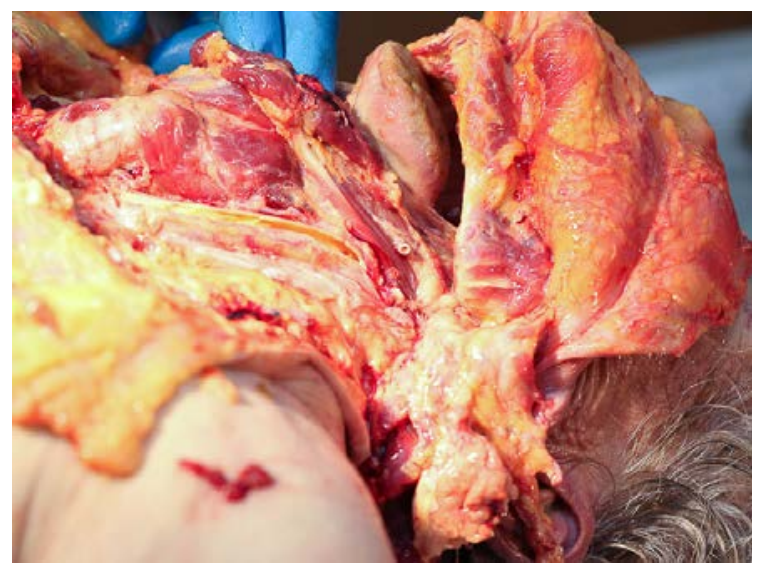

Figura VII.4 - Prolongamento superior da técnica bimastoideia, com exposição do pavimento bucal, língua e ramo horizontal da mandíbula. Cortesia do INMLCF, I.P. 2013. articulação temporomandibular (figs. VII.5) ou secção ao nível do terceiro molar, bem como da maxila mediante um corte ao nível dos seios maxilares acima das raízes dentárias, usando para o efeito uma serra elétrica [36]. Neste contexto, será de considerar a reconstrução facial recorrendo a uma mandíbula pré-fabricada de substituição [16].

De forma a ser possível uma melhor conservação e manipulação dos ossos removidos, é oportuno eliminar os tecidos moles e garantir a sua esqueletização completa [21].

Por fim, no decurso da autópsia bucal pode ser recolhido material para genotipagem, como raspado de mucosa ou remoção de peças dentárias, bem como colheita de amostras de tecidos moles (língua, glândulas salivares ou mucosa oral) para estudo histopatológico [23].

\section{VII.4. PROCESSO DE IDENTIFICAÇÃO HUMANA}

A comparação dentária, tal como sucede com outros métodos de identificação comparativa, deve respeitar critérios científicos, designadamente a presença ou não de pontos de coincidência, discrepâncias ou exclusões [37].

Neste âmbito, importa esclarecer que as discrepâncias correspondem a achados que não concordam entre si, mas que podem, ainda assim, ser de alguma forma explicados (por exemplo, um determinado dente pode estar presente nos registos ante mortem e ausente post mortem, podendo essa circunstância dever-se a este ter sido extraído por outro clínico e não constar da informação clínica disponibilizada). Assim, deverá 
Tabela VII.2. - Principais técnicas de autópsia bucal (adaptado de Oscar Heit) [35].

\section{Técnica comissura-tragus}

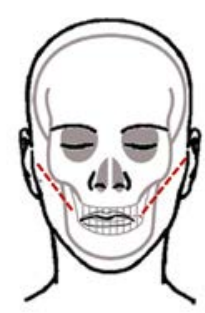

Incisão bilateral única, desde a comissura labial, percorre a região malar e finaliza-se na porção anterior do pavilhão auricular.

\section{Técnica em cunha ou Luntz}

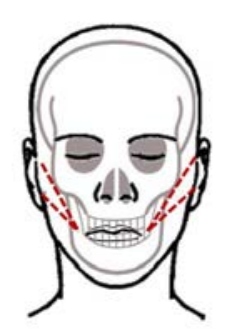

Incisão bilateral dupla, a superior desde a comissura labial, percorrendo a região malar até anteriormente ao tragus do pavilhão auricular. A inferior desde a comissura labial ao bordo inferior do lóbulo da orelha.

\section{Técnica em retângulo ( $1^{\mathrm{a}}$ variação)}

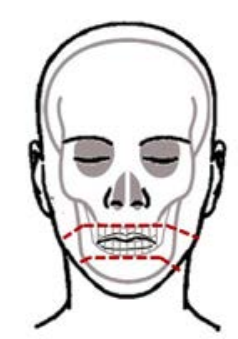

Dupla incisão bilateral: a superior inicia-se por cima do lábio superior e prolonga-se para a linha média até ao bordo inferior do lóbulo auricular; a inferior inicia-se debaixo do lábio inferior e estende-se ao ângulo mandibular. Pode efetuar-se uma incisão posterior para remoção do retalho cutâneo. ser avaliado o grau de discrepância de modo a conferir um poder excludente ou não do mesmo. O processo de identificação humana será tanto mais consistente quanto maior for o número de pontos de coincidência e mais individualizantes forem os achados [38]. A estimativa da idade

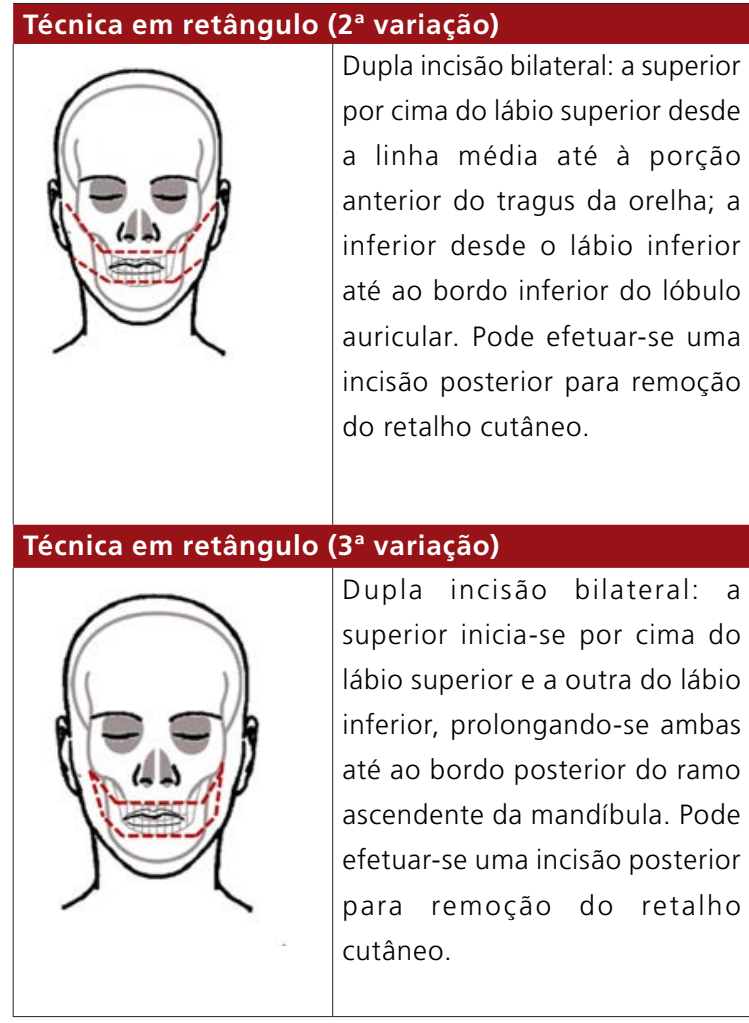

dentária é um dos fatores que pode contribuir para uma identificação positiva das vítimas [39].

Na perspetiva da intervenção médico-legal e forense, para assegurar uma avaliação estandardizada dos processos de identificação, impõe-se a existência de recomendações, em consonância 

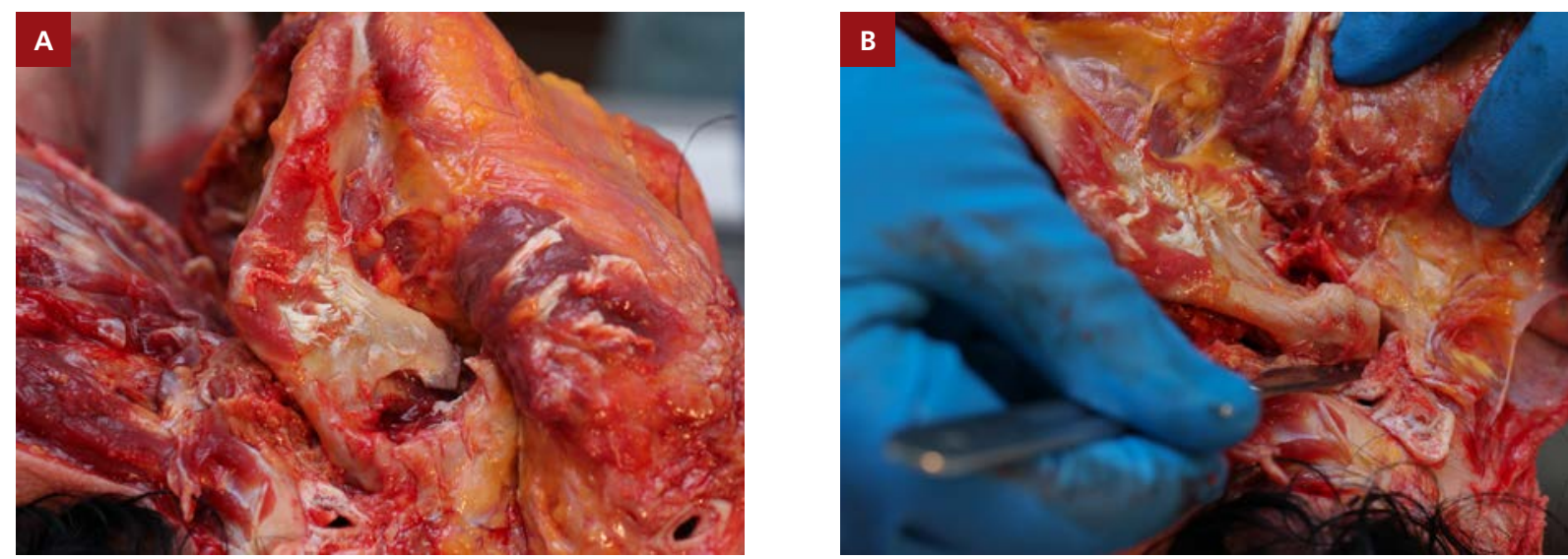

Figuras VII.5 (A e B) - Fotografias durante o procedimento autóptico. (A) Visualização do processo coronoide da mandíbula. (B) Desarticulação da articulação temporomandibular esquerda. Cortesia do INMLCF, I.P. 2013.

com as validadas pela comunidade científica internacional.

Assim sendo, após comparação dentária, o perito médico forense deverá enquadrar o resultado da avaliação tendo em consideração as orientações da ABFO [40] (tab. VII.3).

Por fim, é de reconhecer a possibilidade de erro no preenchimento dos registos clínicos por parte do médico dentista e, neste caso, é importante procurar novos elementos, tais como exames imagiológicos para esclarecimento do caso.

\section{VII.5. LIMITAÇÕES}

A autópsia bucal para efeitos de identificação humana pressupõe a existência de registos dentários ante mortem, com os quais é possível efetuar uma análise comparativa, sendo neste aspeto que residirá, porventura, a maior limitação.

De facto, particularmente em países com menor desenvolvimento da saúde dentária, a probabilidade de obtenção de registos dentários ante mortem completos é reduzida, quer pela desatualização, inexistência ou má qualidade (dados incompletos, discrepâncias e confusão na interpretação dos dados) dos mesmos, quer pela dificuldade no seu acesso [17]. Por isso, a observação de outros sinais físicos de identificação tem vindo a desempenhar uma crescente importância neste âmbito [13].

Um outro aspeto que dificulta o processo de identificação é o recente decréscimo do número de tratamentos dentários invasivos, na medida em que diminui o número de elementos individualizantes. Apesar disso, esta limitação tem sido contornada 
Tabela VII.3. - Resultados obtidos por comparação de registos dentários [40].

\begin{tabular}{|l|l|}
\hline Classificação da ABFO & $\begin{array}{l}\text { Os dados dentários ante e post mortem possuem pontos } \\
\text { de coincidência suficientes que permitem estabelecer } \\
\text { correspondência a um determinado indivíduo, não sendo } \\
\text { identificadas discrepâncias inexplicáveis. }\end{array}$ \\
\hline Identificação possível & $\begin{array}{l}\text { Os dados dentários ante e post mortem possuem pontos } \\
\text { de coincidência, contudo, devido à qualidade dos restos } \\
\text { cadavéricos ou dos registos ante mortem, não é possível } \\
\text { estabelecer-se uma identificação positiva. }\end{array}$ \\
\hline Evidência insuficiente & $\begin{array}{l}\text { A informação disponível é insuficiente para consubstanciar } \\
\text { uma conclusão. }\end{array}$ \\
\hline Exclusão & $\begin{array}{l}\text { Os dados ante e post mortem são claramente } \\
\text { inconsistentes, existindo pelo menos uma discrepância, } \\
\text { totalmente inexplicável. }\end{array}$ \\
\hline
\end{tabular}

com um estudo mais aprofundado de outras características, designadamente a morfologia da câmara pulpar, os limites anatómicos das raízes dentárias e o estado periodontal [41].

Não obstante as limitações referidas, a autópsia bucal mantém um papel relevante no que se refere ao processo de identificação humana, em situações de suspeita de abuso com tradução lesional ao nível dos tecidos periorais e orais e, nalguns casos, para esclarecimento da causa de morte.

\section{VII.6. PERSPETIVAS FUTURAS}

As novas tecnologias na área da imagiologia têm sido preconizadas por alguns autores como complemento das técnicas convencionais de autópsia [41].

Em cadáveres carbonizados ou naqueles com a cavidade oral danificada ou com acentuada rigidez cadavérica mandibular, torna-se extremamente complexa a realização de fotografias e radiografias dentárias intraorais convertendo-se, particularmente nestes casos, a virtópsia num método útil, rápido e fidedigno para obtenção de dados post mortem [42].

Em contraste com a autópsia bucal convencional, a virtópsia permite elaborar um modelo mais preciso das estruturas dentárias, sem danificar a configuração facial do cadáver [42]. A informação obtida, pode ser utilizada para efetuar um estudo comparativo das características individualizantes, bem como para 
proceder à estimativa da idade dentária ou, inclusivamente, para comparação com modelos tridimensionais de mordidas presentes em objetos de interesse [41, 42].

Numa perspetiva mais global da investigação forense, esta técnica pode constituir um meio auxiliar na determinação da causa de morte. Por exemplo, nos casos de vítimas de asfixia por obstrução intrínseca das vias respiratórias, esta prática permite localizar de forma rigorosa o nível de obstrução, evitando alterações da localização decorrentes da manipulação do cadáver [43]. Outros autores salientam a importância deste método na visualização de fraturas do osso hioide ou da coluna vertebral cervical e na deteção de embolia gasosa ou corpos estranhos [44].

Apesar do caráter promissor destas novas tecnologias, estas não se assumem atualmente como um método totalmente alternativo à autópsia convencional, mas sim como um valioso instrumento complementar da investigação forense [45].

\section{VII.7. REFERÊNCIAS}

[1] Fereira, J., Ortega, A., Avila, A. e col. (1997). Oral Autopsy of Unidentified Burned Human Remains. Am J Forensic Med Pathol, 18(3), pp.306-311.

[2] Brannon, R., Kessler H. (1999). Problems in mass-disaster dental identification: a retrospective review. J Forensic Sci, 44(1) pp.123-127.

[3] Chapenoire, S., Schuliar, Y., Corvisier, JM. (1998). Rapid eficiente dental identification of $92 \%$ of 13 train passengers carbonized during a collision with a petrol tanker. Am J Forensic Med Pathol, Dec, 19(4), pp.325-355.

[4] Martin-de las Heras, S., Valenzuela, A., Villanueva, E., e col. (1999). Methods for identification of 28 burn victims following a 1996 bus accident in Spain. J Forensic Sci, 44(2), pp.428-431.
[5] Corach. D., Sala, A., Penacino, G. e col. (1995). Mass disasters. Rapid molecular screening of human remains by short tandem repeats typing. Eletrophoresis, Sep, 16(9), pp.1617-1623.

[6] Ludes, B., Tracqui, A., Pfitzinger H. e col. (1994). Medicolegal investigations of the Airbus A320 crash upon Mount Ste-Odile, France. J Forensic Sci, 29(5), pp.1147-1152.

[7] Clark, DH. (1994). An analysis of the value of forensic odontology in the mass disasters. Int Dent J, 44, pp.241-250.

[8] Gladfelter, IA., Smith, BE. (1989). An evaluation of microdisks for dental identification. J Prosthet Dent, 62, pp.352-355.

[9] Philips, VM., (1993). The role of forensic dentistry in South Africa. Med Law, 12, pp.487-491.

[10] Da Silva, M., (1997). Compêndio de odontologia legal. São Paulo: Medsi.

[11] Wood, R., Tai, C., Blenkinsop, B. e col. (1994). Digitized slice interposition in forensic dental radiographic identification. Am J Forensic Med Pathol, 15, pp.70-78.

[12] Tejaswi, KB., Periya, EAH. (2013). Virtopsy (virtual autopsy): A new phase in forensic investigation, J Forensic Dental Sci, Jul-Dec, 5(2), pp.146-148.

[13] Fereira, J., Ortega A., Avila, A. e col. (1997). Oral autopsy of unidentified burned human remains. Am J Forensic Med Pathol, 18(3), pp.306-311.

[14] Council of Europe Committee of Ministers. (1999). Recommendation $n^{\circ} R$ (99)3. On the Harmonisation of medico-legal autopsy rules.

[15] Ludwig, J. (1861). A handbook of the practice of forensic medicine: based upon personal experience. London: New Sydenham Society.

[16] Knight, B. (2004). Forensic Pathology. ( $3^{\mathrm{a} e d .)}$ London: Arnold.

[17] Paz, J., Fereira, A., Barrios, F. e col. (2005). Conservación de las estructuras orales y faciales del cadáver quemado. Ciencia Odontológica, 2(1), pp. 72-83.

[18] Frari, P., Iwashita, A., Caldas, J. e col. (2008). A importância do odontolegista no processo de identificação humana de vítima de desastre em massa. Sugestão de protocolo de exame técnico-pericial. Revista Odonto.

[19] Morse, D., Esposito, J., Schoor, R. e col. (1993). Comparison of clinical and statistical models in age estimation using dental periapical radiographuc parameters. Compend Cont Ed Dent, 14, pp.832-845. 
[20] Hazebroucq, V., Brown, A., Kannapell, F., e col. (1993). Radiology in the medicolegal Identification of cadavers. A new technique of radiography of the maxilla. J Radiol, 74, pp.671-674.

[21] Pueyo, V., Garrido, B., Sánchez, J.A. e col. (1994). Autopsia, extracción y esqueletización de los maxilares. Odontología Legal y Forense. Barcelona, Masson, S.A., pp. 375-379.

[22] Heit, O. (2011). Autopsias bucales en odontología legal: revisión de técnicas de incisiones. Revista de la Asociacion de Medicos Forenses e la República Argentina, 69, pp. 13-16.

[23] Fonseca, G., Sanchez, M. (2008). Autopsia Buco Máxilo Facial: alcances e inserción en protocolo de Medicina Legal. Ciência Odontológica, pp. 34-43.

[24] Welbury, R.R., Murphy, J.M. (1998 b). The dental practitioner's role in protecting children from abuse. The orofacial signs of abuse. Br Dental J, 184 (2), pp. 61-65.

[25] Jessee, S.A., Martin, R.E. (1998). Child abuse and neglect: Assessment of dental student's attitudes and knowledge. J Dent Children, 65(1), pp.21-25.

[26] Coulthard, P., Warburton, A.L. (2007). The role of the dental team in responding to domestic violence. $\mathrm{Br}$ Dental J, 203(11), pp.645-648.

[27] Welbury, R.R., Murphy, J.M. (1998 a). The dental practitioner's role in protecting children from abuse. Reporting and subsequente management of abuse. $\mathrm{Br}$ Dental J, 184(32), pp.115-119.

[28] Welbury, R.R., Murphy, J.M. (1998 b). The dental practitioner's role in protecting children from abuse. The orofacial signs of abuse. Br Dental J, 184 (2), pp.61-65.

[29] Mouden, L.D. (1998). Family violence prevention: dentistry's attitudes and responsabilities. Quintessence Int, 29 (7), pp.452-455.

[30] Block, R.W., Hibbard, R.A., Jenny, C. e col.(2005). Oral and Dental aspects of child abuse and neglect, Pediatrics, 116(6), pp.1565-1568.

[31] Ricci, L.R. (1991). Photographing the physically abused-child - Principles and practice. Am J Diseases Children, 145(3), pp. 275-281.

[32] Blain, S.M., Winegarden, T., Barber, T.K. e col. (1979). Child-abuse and neglect dentistry role. J Dental Res, 58, p. 367.
[33] Gale, G.L., Noguchi, T.T. (1977). The role of the forensic dentist in mass disasters. Clin Odontológicas Norteamerica, 21, pp.123-135.

[34] Howarth, J.H. (1992). Post mortem identification of a cadaver by use of dental evidence. Br Dent J, 172, p.158.

[35] Heit, O. (2011). Autopsias bucales en odontología legal: Revisión de técnicas de incisiones. Revista de la Asociación de Médicos Forenses de la República Argentina, May, 34(59), pp.13-16.

[36] Prinsloo, A., Gordon, I. (1951). Post-mortem dissection artefacts of the neck. Their differentiation from ante-mortem bruises. S A Medical J, May, pp.358-361.

[37] Eleta, G.V. e col. (2002). Identification en desastres de masas. Cuad. Med Forense, 1(3), pp.167-168.

[38] Frari, P., Iwashita, A., Caldas, J. e col. (2008). The importance of Forensic dentistry in human identification processe of mass disaster victims. Sugestion of Forensic exam Protocol, Revista Odonto, 16(31), pp.38-44.

[39] Valenzuela, A. e col. (2000). The application of dental methods of identification to human burn victims in a mass disaster. Int J Legal Med, 113(4), pp. 236-239.

[40] Bitemark Methodology Guidelines. (2013). American Board of Forensic Odontology, Inc. Diplomates Reference Manual, pp.109-117.

[41] Junior, A., Souza, P., Coudyzer, W. e col. (2012). Virtual autopsy in Forensic sciences and applications in the Forensic Odontology. Odonto Cienc, 27(1), pp. 5-9.

[42] Jackowski, C., Wyss, M., Persson, A. e col. (2008). Ultrahigh-resolution dual-source CT for Forensic dental visualization - discrimination of ceramic and composite fillings. Int J Legal Med, 122, pp.301-307.

[43] Oesterhelweg, L., Bolliger, S.A., Thali, M.J. e col. (2010). Postmortem imaging of laryngeal foreign bodies. Arch Pathol Lab Med, 133, pp.806-810.

[44] Aquila, I., Falcone, C., Di Nunzio, C. e col. (2013). Virtopsy versus autopsy in unusual case of asphyxia: Case report. Forensic Sci Int, 229, e1-e5.

[45] Pomara, C., Fineschi, V., Scalzo, G. e col. (2009). Virtopsy versus digital autopsy: virtuous autopsy, Radiol Med. 114, pp.1367-1382. 